\title{
Introduction
}

The arrival of social networking technologies such as Facebook, MySpace, Twitter, and YouTube is altering the fabric of our lives and changing the ethical implications of our social and political practices. Social media is at the center of many of our greatest public policy debates, but the role it plays in relation to human behavior is far from settled. Consider the shooting attack on Republicans at a baseball field during a charity event. The gunman was described "as a Bernie Sanders supporter and campaign volunteer virulently opposed to President Trump. He posted many antiTrump messages on social media, including one in March that said 'Time to Destroy Trump \& Co.'” (Board, 20I7). A look at his Facebook posts confirmed the antipathy James T. Hodgkinson had for President Trump and the Republican Party. The question not clearly answered, however, was whether social media contributed to his intentions to shoot Republicans. And in the 2016 elections, Hillary Clinton placed some responsibility for her loss on the social media network Facebook. According to Clinton, the "fake stories" that spread on social media influenced the voters in the election. The solution she suggested? Content regulation by the social media giant. She said of Facebook, "They've got to get back to trying to curate it more effectively, they've got to help prevent fake news from creating a new reality" (Staff, 20I7). In response, Facebook and Google began shutting down "fake news" sites, but without a clear understanding of how or why these social media sources played a role in swaying the American voter and without a clear path to avoid the potential regulatory pitfalls that come along with content regulation. Social media and its potentially radicalizing effect also figures into our domestic and international efforts against the threat of terrorism. The Obama administration 
justified the drone strike on American citizen Anwar al-Awlaki, in part because of the radicalizing influence of al-Awlaki's blogs, Facebook page, YouTube videos, and contributions to the online al-Qaeda magazine, Inspire. Even after his death, the Congress believed the influence of social media was so powerful that it had to be taken down to prevent further terrorist acts. A New York Times article affirmed this view, suggesting that al-Awlaki's public statements and videos continued to inspire acts of terrorism in the wake of his assassination (Shane, 2015). Still, the assertion that social media is a source of influence in radicalization does not answer the question of why its influence might be so powerful. Last, but certainly not least, social media is at the center of heart-wrenching circumstances of individuals such as Amanda Todd. Amanda was a young girl who, like many others her age, found an anonymous friend online. After gaining her confidence, this online "friend" convinced her to send a topless picture to him. When the picture went viral, Amanda was bullied and teased to such an extent she was forced to change schools. As the abuse continued, Amanda became more and more despondent and could find no way out of the situation except to commit suicide. Before her death, she made a disturbing YouTube video about cyber bullying that went viral. While many people were shocked and dismayed by what she had experienced, others went on the attack even after her death, suggesting she deserved what had happened to her.

The growing occurrence of diverse incidents such as those described assert a connection with social media, but understanding the reasons for its influence or methods of countering it are far from settled. This is because the approach to the moral problems we encounter in our use of social networking technologies is founded on familiar fault lines that continue to limit our inquiry. The potential mediating effects of social media on $u s$, the choices we make, and the actions we take is not fully interrogated because, despite the disagreement about the ethical concerns of social networking technologies for society, there is one assumption that has been generally accepted by those engaged in the debate: social networking technologies lack moral significance.

The moral significance of technologies generally - not only social networking technologies - is difficult to explore because technologies are typically considered objects and we are human, and the province of morality has long been ours. We viewed technology as only a tool capable of freeing us from our human limits, providing us with an increased ease in communication, commerce, or transportation. With this view in mind, we have addressed the morality of our machines, working to limit their 
detrimental effects on the existence of humanity to ensure our morality is not destroyed. We have developed disciplines to address our ethical concerns, such as bioethics, nanoethics, cyberethics, and hackerethics, to guarantee that technology is under our moral direction and control. Not surprisingly, the narrative about social networking technologies and the types of human interactions they engender is focused on how we employ the technologies and the moral consequences we cause rather than the moral significance of the technology on our existence, experience, and perception. These technologies are at one and the same time portrayed as a threat to our privacy and anonymity and protective of them; essential and destructive of our interpersonal relationships; and simultaneously constructive of a global civil society and debilitating to it. Social media is often intimately connected to the expansion of our freedom and liberty in cyberspace just as often as they are designated threats, as reports of surveillance, data mining, and information sharing continue to escalate. Those like Gabriella Coleman defend a broad range of human activities on the Internet- even those considered harmful by many - as morally and politically consistent with a Western tradition of freedom of expression and protest, no matter how damaging or offensive the consequences. She wrote:

A decade-plus of anthropological fieldwork among hackers and like-minded geeks has led me to the firm conviction that these people are building one of the most vibrant civil liberties movements we've ever seen. It is a culture committed to freeing information, insisting on privacy, and fighting censorship, which in turn propels wide-ranging political activity. In the last year alone, hackers have been behind some of the most powerful political currents out there (Coleman, 20I3).

Others focus on the harmful human behavior behind the technology. Citron, for example, points to the fact that the "Internet has contributed to the rise of bigoted mobs. People are more inclined to join antisocial groups when they do not have to disclose their identities" (Citron, 20I4, p. 62).

The present work provides a new perspective by offering a new approach for conceptualizing the moral significance of social networking technologies and so that we can develop a new trajectory for future research. The central premise is that mediation of social networking technologies possesses phenomenological effects significant to the actions we take and the decisions we make in a morally significant way. The phenomenological effects are of no small consequence, raising questions about how and under what circumstances we are shaped by social media, 
which ultimately changes the perspective we take on moral responsibility for online behavior and challenges our current approach to regulation and technological development. At a time when our communications, interactions, and transactions increasingly rely upon the medium of technology, it is essential to begin to understand whether and in what ways our technological tools might affect our own sensibilities about morality.

Consideration of the moral significance of technological artifacts requires defining an alternative to the modernist subject-object dichotomy upon which our relationship with technology has long been premised. This does not necessitate attributing animism to technology, but instead requires us to evaluate how and under what conditions and to what effect technology mediates the reality we encounter online. Although technology lacks consciousness, rationality, freedom, and intentionality, it does not follow that technology does not have an important moral dimension in influencing "human actions and experiences" and shaping our moral choices even in the most innocuous ways (Verbeek, 20II).

Instead of a classical phenomenologist account that seeks to describe preexisting subjects and objects, a postphenonmenological viewpoint, like that taken here, analyzes technology as constructive of human behavior and engages a more contextualized approach to technology through which subjectivity and objectivity are constituted (Ihde, I993). To evaluate the mediating effect of communication technologies on our perception of reality, it is necessary to view the relationship not as unidirectional, but instead as one in which technology acts upon us as we act with it. As Verbeek explains, "technological artifacts are not neutral intermediaries but actively coshape people's being in the world: their perceptions and actions, experience and existence" (Verbeek, 20I I, p. 8). Technologies mediate not only our perceptions, but also our praxis, introducing a novel set of considerations to the question of means, ends, and morality that has animated the study of technology and its effect on our lives. The chapters that follow provide a foundation for rethinking the moral significance of social networking technologies with the intention of establishing the basis for reconsidering the technological influences on our own morality.

\section{Methodological Approach}

Chapter I considers how and under what circumstances the political significance of communication technologies has so far dominated our ethical concerns associated with social networking technologies. While 
the political significance of communication technologies in general is obvious, this singular approach clouds our ability to engage in alternative methodological inquiries. Coming to terms with the moral significance of technologies has been difficult to explore primarily because these same technologies are at the center of existing cultural, political, and social debates that draw our attention to the political rather than moral significance of communication technologies.

The political significance of any given technology is found in the social and material conditions necessary for the operating environment of the system and in the social and political relationships constructed around it. As Winner explains, "if we examine social patterns that characterize the environment of technical systems, we find certain devices and systems almost invariably linked to specific ways of organizing power and authority" (Winner, I986, p. 33). Some of these social and political patterns are longstanding. The practice of coupling technology and the power of the state occurred as far back as Plato: "a pivotal theme in the Republic is Plato's quest to borrow the authority of techne and employ it by analogy to buttress his argument in favor of authority in the state" (Winner, I986, p. 30). Decoupling technology from its political significance, however, is not a simple matter because it is often intricately intertwined with patterns of social and political authority vested in it which, in turn, influences our understanding and praxis. Likely, we may not even recognize the entrenched ways in which we attach political significance, taking it to be part and parcel of the technology rather than something that is constructed around it:

Histories of architecture, city planning, and public works contain many examples of physical arrangements with explicit or implicit political purposes. One can point to Baron Haussmann's broad Parisian thoroughfares, engineered at Louis Napolean's direction to prevent any recurrence of street fighting of the kind that took place during the revolution of I 848 . (Winner, I989, p. 24).

Early communication technologies such as the telephone, for example, served existing patterns of political authority by providing new tools to law enforcement to ferret out illegal activity during the Prohibition era and to investigate allegations of espionage during both of the Red Scares. The political significance of communication technologies was not only a matter of state authority. The same technology also enabled new societal patterns of associational life that evoked the political significance of First Amendment freedoms and Fourth Amendment privacy protections. Modern social networking technologies evidence some of the same forms 
of political significance attributed to the telephone, but the arrival of Facebook, Twitter, Snapchat, and Instagram also introduced new patterns of social and political authority as the private sector increasingly plays an important role in the information revolution. Communication companies and Internet service providers develop a never-ending supply of social networking platforms and apps for the anxious consumer, who willingly trades his or her data for access, leading to information harvesting and mining for the benefit of the private sector, but also for the public sector as incidences of clandestine information sharing with the government are uncovered. The American Civil Liberties Union (ACLU) of California, for example, recently discovered that Twitter, Facebook, and Instagram provided user data access to Geofeedia, a developer of a social media monitoring technology put to use by law enforcement to track protesters and their associational networks. Individuals, however, are not entirely powerless in this new information economy and are creating their own solutions for protecting their privacy and associational rights by ironically using the very same technological tools to obfuscate identity and communicate anonymously. Anonymous communication technologies, including such things as web-based redirectors, protocol dependent proxies, and Tor or virtual private network (VPN) tunneling are increasingly used as a technological panacea to the erosion of privacy on the Internet. By some accounts, there has been a sixfold increase in the demand for VPNs, especially in light of the rollback of congressional protections for privacy. This trend continues despite the fact that the privacy protections gained are not always as protective as they are represented (Silverman, 20I7).

While social networking technologies are rightly viewed through the prism of the past because they are vested with some of the same political significance of their antecedents, our present and future relationship with these technologies should not be limited to only this perspective. The focus on the political significance of the past for understanding social networking technologies of the present is not necessarily incorrect, but it does have the parallel effect of diminishing our consideration of the moral significance of these more modern forms of communication technologies. To pave the way for a newly conceived approach to social networking technologies, the old must be reconsidered, and this first chapter is intended to set the stage for a reconsideration of the moral significance of social networking technologies.

Chapter 2 develops a theoretical approach for evaluating the moral significance of our new forms of communication technologies. Works such as Latour and Woolgar's Laboratory Life (1986) or Michael Lynch's Art 
and Artifact in Laboratory Science (1985) establish the basic assumptions of the approach taken here, which is built on the premise that technology cannot be isolated from methods, interests, materials, and institutions influencing its constitution; rather, technology is an artifact arising from the complex interaction of these processes and interests and should not be separated from the intentionality of users, policy, methods of adaptation, and existing institutional practices that influence its constitution. The first step in constructing a framework to understand the mediating influences of technology on our experience, perception, and existence is to dismantle the modernist subject-object dichotomy upon which our relationship with technology has long been premised. This process formally begins with a consideration of Heidegger, who establishes a philosophical basis for understanding the relationship between human beings and their technological tools as something more complex than subjectobject dichotomy. In his essay on The Question of Technology, he warns that an instrumental conception of technology is a limitation on our understanding of technology's essence. Heidegger explains his reasoning:

We are delivered over to it in the worse possible way when we regard it as something neutral; for this conception of it, to which, today we are particularly likely to do homage, makes us utterly blind to the essence of technology (Heidegger, I977, p. 288).

Heidegger suggests our relationship with technology is one that orders our understanding of reality and, in doing so, also influences our relationship with Nature and our own sense of Being. Heidegger sets aside the usual starting point of the subject-object dichotomy and instead assumes technology influences our perceived reality, which is continually revealed as we investigate and observe with the use of technology. Heidegger's insights provide the basis for a phenomenological approach to the study of technology in the tradition of Edmund Husserl and Maurice MerlouPonty, both of whom advocate on behalf of research that "analyzes the relations between human beings and their world rather than a method of describing reality" (Verbeek, 20II, p. I5). These insights are taken one step further in a postphenomenological approach to technology. Not only is reality influenced by the lens of technology, but so too is humankind changed in our day-to-day use of technology. According to this viewpoint, technology is not a mere tool but is also a medium through which subjective perceptual experience is created and mediated, which, as will be discussed, possesses consequences for our moral sensibilities. As Don Ihde describes, whether by a process of embodiment, hermeneutics, or 
alterity, technology can transform our experience of reality and affect our existence in the process. The postphenomenological explanation of our relationship with technology is built on the premise that it is transformative of our perceptions, existence, and experience:

From a hermeneutical perspective, artifacts mediate human experience by transforming perceptions and interpretive frameworks, helping to shape the way in which human beings encounter reality. The structure of this kind of mediation involves amplification and reduction; some interpretive possibilities are strengthened while others are weakened. From an existential perspective, artifacts mediate human existence by giving concrete shape to their behavior and the social contexts of their existence. This kind of mediation can be described in terms of translation, whose structure involves invitation and inhibition; some forms of involvement are fostered while others are discouraged. Both kinds of mediation, taken together, describe how artifacts help shape how humans can be present in the world and how the world can be present for them (Verbeek, 2005, p. I96).

The current research suggests the mediating effect of technology also requires rethinking our basic assumptions about the autonomy of the moral subject in any debate about ethics and technology. If technology alters our sense of identity, agency, intention, and consciousness, affecting how we evaluate the actions we take, the phenomena we encounter, and the judgments we make, then there is a consequence for how we conceive of and assign moral responsibility in our online lives. There is some precedent for this way of thinking about technology in the work of Bruno Latour, who considered seriously the moral significance of technologies in the effects exerted on our practices and habits. Latour takes his cue from Heidegger and suggests that our relationship with technology can be better explained with a concept of networked reality to capture the complex ways humans and nonhumans are intertwined and, more importantly, how nonhumans can also be moral agents. According to Latour's theory, technologies form "scripts" that encourage users to act in particular ways. Though the intention of the user is not overridden by the script of the technology, there exists a network between the two that then allows for the technology to take on moral significance (Latour, 2002). This idea of moral significance is extended further by Verbeek, who, in his consideration of obstetric ultrasound, argues technology constructs "a modern, heteronomous moral subject whose actions are always interwoven with the material environment in which they play out" (Verbeek, 2OII, p. 22). Verbeek calls the association between humans and reality the "interpreted reality" and human existence "situated subjectivity." His example of a sonogram illustrates how and for what reasons 
technological mediation can make moral dilemmas apparent and acute, demanding decisions about genetic defects, such as Down Syndrome and more in the course of a pregnancy, where before technological mediation there might have been none (Verbeek, 20II). His postphenomenological approach "moves beyond the predominating modernist understanding of the relations between subjects and objects in ethics, in which subjects are active and intentional and objects are passive and mute" (Verbeek, 20I I, p. I6). The present work takes the insights of Verbeek and Latour to provide the philosophical justification for the morally significant mediating role of social networking technologies on perception, existence, and experience of reality online and for the consideration of the consequences for our own morality.

Chapter 3 takes up the issue of human agency online and considers the mediating effect of social networking technologies on the ways in which we form our intentions, beliefs, and reactive attitudes. These technologies may allow us newfound freedom, liberating us from the physical constraints of real time and space, but there also may be unintended consequences for us. This is not to say human agency is destined to be harmful or contentious when mediated by social networking technologies; rather, it is to tease out the differences that might be relevant to the formation of our intentions, beliefs, and reactive attitudes online. Whether human agency can be affected by the circumstances within which it is exercised is not entirely novel. Modern philosophy has long wrestled with the perennial tension between free will and determinism and has struggled to understand when free will has been shown not to be entirely free because of the limiting or enabling effects of its physical reality. Hume, for example, observed that if actions are produced by motives, and motives are linked to the physical phenomenon, then free will, where "liberty which is opposed to necessity," cannot be used to characterize human action (Hume, I907, p. I00). A similar sort of tension exists when evaluating the enabling or limiting effects of social networking technology on human agency. If the mediating role of technologies affects the formation of our intentions, beliefs, and reactive attitudes, how should we account for the moral qualities of the technology and understand its effects on human agency? P. F. Strawson's insights in his article "Freedom and Resentment" and some of the many critiques that followed are also helpful to considering how and why our online communications might affect how we form our intentions, beliefs, and reactive attitudes behind collective and individual human agency and how we conceive of moral responsibility. According to Strawson, 
the idea of holding individuals responsible is part of our political and social practices and "neither calls for nor permits, an external 'rational' justification" (Strawson, 1992, p. 23). From this point of view, human agency exists in our reactive attitudes and the moral judgments we form about individuals; this "central commonplace" is a helpful basis for understanding how and under what circumstances the capacity for human agency exists even in the face of causal constraints. A person may hurt us physically or emotionally, for example, but we are more inclined to temper our reactions if the action was not intended or was misdirected (Bennett, 2008). Consider the implications of the "central commonplace" when it forms online. As we shift our interactions to an online forum, our knowledge of individuals and the reasons behind their actions is affected. We may understand little about those with whom we interact and, at the same time, the images or phenomena we encounter online may be presented in a way that engenders intense reactions that lead us to believe there is a widely shared sense of morality when, in fact, there is a relatively narrow perspective generated by the online community with whom we are interacting. Both of these phenomenological effects can influence the kinds of moral judgments we make and the beliefs, intentions, and reactive attitudes we form that we use to inform our actions. We may want to attack an individual online for what we perceive as their moral wrongs, but the judgments we form or the information we use to make them may be, at best, based on distorted information or, at worst, completely misinformed because of the shallowness of our understanding. The nature of our relationships (subjective versus objective, individual versus collective) has an important consequence for the moral judgments we make and the blame or lack thereof we might attribute to our actions, and this is especially true when we move online.

How we evaluate the causal responsibility for our actions online is also important to understanding the effects of virtual reality on human agency. Hume, for instance, speaks to the kinds of mistakes we make when we perceive will as a causal mechanism, and this problem is exacerbated in our online actions but perhaps in the inverse way. We may misapprehend the causal mechanism of our behavior online or underestimate its devastating effects on others. We may even attribute will where there is no intention or attach blame to others where there is none. Our own sense of blameworthiness might even be ignored because we do not see ourselves as responsible. The perception of causal connection between our behavior and the effects may be altered in our online communications (one posting exists indefinitely online) or our behavior 
may be only one causal mechanism among many intentions combined (cybermobs), or we may intend to cause one thing but it may result in just the opposite. These usual referents for our agency or the displacement of them by collective action online can divorce our intention from its consequences and separate us into subjectively created communities that may be very different from the real places we inhabit and the real people with whom we interact. Our online communications may also create the conditions of power over others where none existed before, something Locke discussed in his attempt to modify the traditional notion of contracausal freedom with a softer notion of free will that considered the power of an individual to carry out his or her own intentions. In the "Idea of Power," Locke argues that liberty is not an idea belonging to volition or preference, but to the person having the power to do (Smiley, I992). He explains that "the idea of liberty is the idea of power in any agent to do or forbear any particular action, according to this determination of thought of mind, whereby either of them is not in the power of the agent to be produced by him according to his own volition, there is not liberty ... the idea of liberty reaches as far as that power and no further" (Locke, I 856 , p. I 56). The exertion of our "power" online may have devastating consequences without the restraint we encounter in our offline lives. If social networking technologies mediate our intentions and beliefs and shape our reactive attitudes and beliefs about individuals, phenomena, and causation, then should we think about human agency and its regulation differently when it takes place in cyberspace as opposed to real time and space? These kinds of questions are not only philosophical in nature; they are fundamental to reconsidering how to deal with some of the regulatory challenges in cyberspace instead of treading the same ground on which we continually argue about the morality or immorality of online behavior without considering the mediating role of technology.

Chapter 4 considers how networked time affects our perception of past, present, and future in our online interactions and, in doing so, transforms our perceptions, experience, and existence. This chapter represents a continuation of a century-long discussion about time consciousness and its consequences about the reality we perceive and interpret, beginning with Saint Augustine, who struggled with the perception of time and its relationship with eternity. Time and how it is affected by human perception has been an ongoing facet of sociological accounts of postmodern society, but networked time might even be more transformative of our praxis and our morality than ever before. The basic premise is that postphenomenological epistemology is the starting point and 
assumes consciousness plays an active role in constituting the phenomenon it observes and encounters. The issue is whether our consciousness is altered by the asynchrony of virtual reality. The type of context-bound temporal experience we encounter in our online interactions represents a departure from the usual time and space restraints. But where temporality is an unavoidable consequence of experience, does virtual reality represents a significant transition in our thinking about morality? In real time and space, when an individual makes a judgment, whether it is about the consequences of his or her behavior on others or about phenomena encountered, the material constraints of the co-present exist. Online communication organized around temporally isolated and attenuated exposure to phenomena or to the Other may have the hermeneutical effect of narrowing our sense of ethical and social responsibility, affecting the judgments we make and the actions we take or the things that we say while online, putting the emphasis on a temporally isolated present. The implications for morality are important. Time figures significantly in contemporary discussions involving man in meditation upon his destiny and that of humankind because moral responsibility is a function of contemplation of our actions, not temporally isolated in the present, but in consideration of the effect of our actions across a spectrum of time and space. Umberto Eco, for instance, suggests that "the subject situated in a temporal dimension is aware of the gravity and difficulty of his decisions, but at the same time he is aware that he must decide, that it is he who must decide, and that this process is linked to an indefinite series of necessary decision making that involves all other men" (Eco, I979, p. I I3). If networked time represents a transition not only in our consciousness of time but also allows us to focus on an abstracted and temporally isolated present to the exclusion of material co-present reality, the issue is whether our reactions to phenomena, the Other, evaluations of consequences, and ultimately our own sense of morality are also altered.

Chapter 5 evaluates some of the ethical consequences of moving our personal identity online and how we might create the conditions for moral responsibility in virtual reality, which, in the end, involves thinking about the source of our normative assumptions. In a virtual world in which human interactions are increasingly performed in the abstract and technology extends our being and presence in ways that are separate from our personal identity grounded in real time and space, there are important assumptions to reconsider about how we conceive of moral responsibility and how a postphenomenological point of view lends perspective. This chapter begins with a historical review of personal identity, 
which has long been connected to discussions about the assignment of moral responsibility. As John Locke wrote, "in this personal identity is founded the right and justice of reward and punishment" (Locke, I 82 I, p. 34I). Locke's viewpoint on personal identity reflects the tendency in the Western intellectual tradition to ground personal identity in consciousness, which is ontologically separate from the world around us. For Locke, personal identity was defined in terms of memory and the ability to self-reflect on our actions. He explained that personal identity is defined by the qualities of a "thinking intelligent being that has reason and reflection, and can consider itself as itself, the same thinking thing, in different times and places." (Locke, I 856, p. 286) But what role does this consciousness play in our virtual lives? Some have suggested our virtual lives expand the idea of the social (Fernback, 2007; Rheingold, I992; Turkle, I995). The hope was that this new social space would offer the potential to relate to others without the usual physical or time constraints and provide "tools for facilitating all the various ways people have discovered to divide and communicate, group and subgroup and regroup, include and exclude, select and elect" (Rheingold, I992 p. 62). As human beings, we are self-conscious about the reasons for which we act, and as a result we reflect on the desires we have because of the effects we might have on others and ourselves. Yet, if our online personal identity is a product of our self-conscious creation of it without the usual material constraints of time, space, and proximity around which the relationship between personal identity and moral responsibility have long been constructed, what are the consequences for morality? Social networking technologies allow us to structure our human interactions in ways that differ from our real-time and space existence, but if we are able to isolate our virtual selves from our physical selves, then the assignment of moral responsibility is also complicated. Our online identity is oftentimes contingent and does not possess the same kind of necessity of being a unified agent that characterizes our lives lived in real time and space. The relationship between personal identity and moral responsibility in our material lives may seem straightforward, but where personal identity is muddled by different monikers or displaced by anonymity or aspirational identities that forge a separation between our online and offline selves, how should we conceive of moral responsibility?

The issue of discontinuity of personal identity and moral responsibility is not entirely new. There has been a long and detailed discussion about how and under what circumstances individuals should be held morally responsible for their actions if and when there is discontinuity 
of personal identity. Usually, the concern in philosophical debates is whether or not to hold an individual morally responsible if there is some discontinuity in their personal identity because of factors affecting psychological connectedness and continuity in the form of memories, intentions, or other mental states. The reductionist view maintains that a person persists through time as a function of memories, beliefs, intentions, and other mental states (Radden, I996). From this perspective, personal identity is considered "slices" of individuals across time and space, where moral responsibility is segmented according to the slices of psychological connectedness and continuity. Nonreductionists, on the other hand, maintain that a person is a separately existing entity, and that personal identity over time cannot be analyzed into disparate pieces and is instead ontologically based. Concerns about psychological continuity and connectedness arise with regard to personal identity because an individual who is impaired should be held to a lower standard of moral responsibility. In some ways, the difference in viewpoint between the reductionists and nonreductionists is analogous to our quandary about personal identity when it comes to online behavior. Online communication allows for a self-conscious disconnect from our personal identity organized around the dictates of real time and space; this only grows more commonplace as the methods of communicating online multiply, enabling our identity to be diced, spliced, and chopped into temporally dislocated pieces. The prospects of anonymous communications introduce even more complex considerations for moral responsibility and personal identity. One of the earliest indications of the consequences of anonymity in our physical lives was the deindividuation effect on individuals, which was demonstrated by Zimbardo (1969) in his electric shock experiment. According to his deindividuation theory, Zimbardo placed strong emphasis on anonymity as the cause of diminished concern for self-evaluation, which enables individuals to act with disregard for following societal norms of behavior. That is, external and internal constraints that would typically regulate questionable behavior are rendered less effective because anonymity allows for the inhibiting effects of the social environment to disappear, attenuating shame, guilt, and fear.

While Zimbardo's research asked individuals to conform to the researcher's expectation to shock another individual while remaining anonymous, more recent studies about online anonymity have shown it can cause us to engage in more uninhibited behaviors, including violence, aggression, and sexual self-disclosure, when we interact in virtual reality. 
The obvious criticism of this line of argument is that most of what we think occurs anonymously is not actually anonymous - there are many means of reconstructing personal identity if necessary, making us not as unknowable as we might want to be. When individuals believed (regardless of the veracity of this belief) their identities were not known to others, there was a greater tendency to send hostile and threatening messages in chat rooms or through instant messaging. This deindividuation effect on individuals might be exacerbated when a group of individuals coalesce around a moral or political position and their positions are affirmed by those with whom they are interacting. But there may be more to the story than simply anonymity. The kind of behavior we see online might also be a function of the kinds of online communities we join and identities we adopt based not on our physical proximity, but instead an imagined community that is not only about a sense of connectedness but exclusion as well. There is evidence that members of a marginalized group can use a group identity to resist a more powerful majority group, for example, by forming attachments as the basis of the group identification, which has a consequence for collective action on the Internet (Postmes, 2005). If individuals create and negotiate their identities through an iterative process of dialogic and symbolic exchange with other individuals while online, it does not always follow that the group dynamics are positive, however. Coffey and Woolworth (2004) found marked differences in the level of vitriol when they compared the dynamics playing out in a physical town meeting from the kind of online behavior that occurred on an anonymous message board for community members in the wake of a murder spree. Others such as Citron have pointed to the tendency online for group dynamics to take hold, creating a mob mentality and fueling abusive behavior online as competition for recognition and antisocial behavior are encouraged (Citron, 20I4). The basic dilemma of our online personal identity is that when we think about moral responsibility we assume a unity of an agent to whom we assign moral responsibility for the choices made and actions taken. But if personal identity is not coherent in its many online forms or can be obfuscated with the use of communication tools or more generally because of the sheer numbers of interactions we have, do we also need to think about the assignment of moral responsibility differently?

Chapter 6 considers the traditional regulatory approaches to social networking technologies and posits ways in which we may need to modify our approach to capture the consequences of their moral significance on us. More importantly, however, social media also reveals 
something about us and the normative reasons we construct for our morality. The modernist assumptions about our relationship with technology are mired in a dichotomous approach, ranging from those who champion the highly unregulated space of the Internet to those who argue for the need to rein in human behaviors to which this unregulated space gives rise. The current policy debate is premised upon the autonomous moral subject and is oftentimes dominated by traditional concerns of free speech, anonymity, and our privacy interests in our personal information while trying to temper harmful online behavior such as cyber bullying, digilantism, threats, racism, and terrorism without trampling on these traditional freedoms. It is not surprising that these First Amendment freedoms and our privacy interests in our personal information figure centrally in the debate about social networking technologies. Privacy and First Amendment freedoms are strongholds of a civil society. Free speech and anonymity, for example, were central to our constitutional founding. During discussions about the United States Constitution after the failure of the Articles of Confederation, essays and pamphlets published under pseudonyms were designed to kindle the fires of political deliberations. The Anti-Federalists, fearing retribution from their Federalist counterparts, argued about the future composition of the constitutional framework while remaining under the cover of anonymity. Since then, the right to remain anonymous has been an important aspect of First Amendment jurisprudence, and its preservation has often been used to prevent a chilling effect on democratic participation and speech. Because anonymity protects a sense of liberty to freely associate and protects decisional autonomy, serving an important purpose in preserving some degree of private space for political opposition and the expression of ideas especially during times of political strife, those such as Froomkin continue to make the argument that anonymity is powerful for securing essential aspects of individual freedom even when we move online:

The arguments for why untraceable anonymity is a good thing include the idea that it contributes to human flourishing; people want to experiment, and the ability to experiment with less fear contributes to human self-realization. In places that are less free, avoiding retribution for saying the wrong thing may be a matter of life and death. Political dissidents, ethnic minorities, religious splinter groups, people campaigning for women's rights or gay rights, and many others are, or have been, subject to the risk of genuine and very palpable violence. If they wish to speak or write for their causes they need a means to protect themselves. Anonymity is one such tool (Froomkin, 20I5, p. I2I). 
These ideals are no less important when it comes to our online lives and are important means of avoiding the self-disciplining effects of surveillance first described by Jeremy Bentham, who proposed the use of a panoptic tower in a reformatory. Bentham, of course, recognized the benefits of surveillance and pointed to the fact that prisoners would never know with certainty if they were being observed by one guard, many, or none at all. As a technique of the modern state, Bentham highlighted the self-disciplinary effects of observation on individual behavior as a benefit of the architecture of surveillance. This concept was later appropriated by Michel Foucault, who described the normalizing and constraining aspects of the power of observation, which served to limit the subjectivity, and thus liberty, of individuals in modern society:

He who is subjected to a field of visibility, and who knows it, assumes responsibility for the constraints of power; he makes them play spontaneously upon himself; he inscribes in himself the power relation in which he simultaneously plays both roles; he becomes the principle of his own subjection (Foucault, I995, pp. 202-3).

In addition to the guarantees of First Amendment freedoms, the right of privacy has long been identified as a key component of human dignity and has been described as a right "older than the Bill of Rights." (Griswold, 38 I U.S. at 486). Under the law, privacy in different forms has received protection under the First Amendment, which protects freedom of conscience; with the guarantees of the Fourth Amendment, which guard against unconstitutional searches and seizures; and with a host of statutory and common law protections. Despite these legal guarantees, the concept of privacy has also long been contested and debated as discontent over existing protections prompted debate and reconsideration of its significance in modern life, broadening its legal protections to include control over information; intimacies of personal identity; physical or sensory access; protection against searches and seizures; solitude; freedom from surveillance; and others (Schoeman, I984). This evolution of privacy is a result of many discussions of instances where the law as it stood did not entirely protect privacy as society thought it should. Then as now, technological innovations, changing conceptions of personhood, and shifting norms, values, and expectations have all challenged conceptions of privacy and directed changes in legal doctrine, but these do not diminish privacy's continued importance, especially in the age of information. 
The Internet and social networking technologies introduce another layer of complexity as to how anonymity, free speech, and privacy should continue to matter, however. Those such as Froomkin suggest that anonymity is threatened by the perfect storm of surveillance technologies, national security concerns, and the increase in data harvesting and mining by the private sector, the consequence of which is an erosion of liberty and freedom in our lives if we do not retain the protection of anonymity. In reference to privacy, there are also questions about whether the current regulatory approach should also be changed. Sklanksy, for instance, makes the point that privacy must be reimagined because "a helpful conception of privacy should include, elements that are missing from an account of privacy that focuses only on control over data flows" (Sklansky, 20I4, p. I I07).

There are ways in which social networking technologies are changing us even as we struggle to control them. Sousveillance, or mob vigilantism or participatory panopticanism, might also be characterized as yet another threat to our online lives that our current approach does not fully address. The novel question presented by sousveillance is whether the constancy of observation and the possibility of online harassment and cyber bullying by others in cyberspace results in a newly conceived chilling of associational life and freedom of speech in virtual reality that is distinct from our usual concerns about governmental surveillance. And, moreover, these phenomena raise the question of whether they may be damaging the associational life upon which a free society depends. Even some of our political philosophers, including John Locke, noted that vigilantism could be considered a legitimate and sacred defense against arbitrary power:

Whoever uses force without Right, as everyone does in Society, who does it without law, puts himself into a State of War with those, against whom he so uses it, and in that state all former ties are cancelled, all other Rights cease, and everyone has a Right to defend himself, and to resist the aggressor (Locke, I82 I, p. 232).

Still, vigilantism is not always so gallant, and this is especially true in our online digilantism. The protections afforded to us in our online lives also serve the purposes of our attackers, and like its historical predecessor, vigilantism, where our tendency toward human fallibility is apparent in the mistaken moral judgments we make. It is perhaps an unsettling truism to say that a sound cause becomes bad if supported by "bad" men and an unsound cause becomes good if supported by "good" (Commanger, 
I958, p. 98). The "Know Nothing" movement, for example, was organized around the principle of limiting or ending the influence of Irish Catholics and other immigrants on American politics. Lynch mobs, the Vigilance Committee, the Citizens' Council, and the Klan are just a few examples of vigilantism gone wrong. As Locke warned, "the power that every individual gave the Society, when he entered into it, can never revert to the individual again, as long as the Society lasts, but will always remain in the Community; because without this there can be no Community, no Commonwealth, which is contrary to the original Agreement" (Locke, I $82 \mathrm{I}, \mathrm{p}, \mathrm{I} 47)$. Suffice it to say that vigilante movements cannot be for personal aggrandizement or private gain - otherwise, damage to the community is the end result. Humans are, unfortunately, all too human, and whether we are online or offline, the damage done can be detrimental. Still, the call to fend off the bad behavior tends to follow a common regulatory approach.

Any regulation of the Internet, however, is to some the greater evil to be avoided. Gabriella Coleman, for example, argues that "the hacker underground demands recognition for their exploits - even anonymous recognition - because transgression is the method of self-assertion." She frames transgression as a principle consistent with the teachings of John Stuart Mill, whom she describes as defining "the free individual as one who develops, determines, and changes his own desires and interests autonomously through self-expression, debate and reasoned deliberation" (Coleman and Golub, 2008, p. 269). When harm is the consequence of the exercise of individual liberty, one wonders whether Mill would favor this expression of freedom. He writes, "the only purpose for which power can be rightfully exercised over any member of a civilized community, against his will, is to prevent harm to others" (Mill, I865, p. 6). In response, Coleman and Golub suggest we should not focus our attention on "a putatively homogeneous set of norms, values, and practices." Instead, we need to consider that those who engage in expression on the Internet, no matter what its harm, evoke broader themes consistent with our political sense of right and good including free speech, meritocracy, privacy, and the power of the individual, all of which represent "reworked liberal ideals which ultimately create a diverse but related set of expressions concerning selfhood, property, privacy, labor, and creativity" (Coleman and Golub, 2008, p. 267). Those like Coleman want to generally avoid any constraint on what they take to be the Internet's generativity. From this viewpoint, when a technology has the capacity to allow its users to innovate in ways not imagined by its developers, the imposition of any 
regulatory restrictions undermines this process. Jonathan Zittrain, for his part, fears the loss of generativity in the future of the Internet with conscious consideration of how we build and regulate it:

Generativity pairs an input consisting of unfiltered contributions from diverse people and groups, who may or may not be working in concert, with the output of unanticipated change. For the inputs, how much the system facilitates audience contribution is a function of both technological design and social behavior. A system's generativity describes not only its objective characteristics, but also the ways the system relates to its users and the ways users relate to one another. In turn, these relationships reflect how much the users identify as contributors or participants, rather than as mere consumers (Zittrain, 2008, p. 7I).

These regulatory debates are familiar and somewhat comfortable because they are reflective of the approaches we have taken in the past when regulation of technology is pitted against First Amendment concerns and privacy interests, but they do not capture the moral significance of social networking technologies and their effects on us and, further, what we might learn from them. The main intention of the present work is to develop a framework for considering the effects of social networking technologies on our experience, existence, and perception beyond the usual constraints of the current debate. This postphenomenological approach broadens the questions we ask not only about our relationship with social networking technologies but also what drives our search for morality, understanding that currently tends to reference the existing social and political patterns of the past that have so far conditioned our approach to communication technologies legally and morally. To simply argue that we must treat online behavior in the same manner as we have treated First Amendment freedoms and privacy interests in real time and space is to miss the mediating effect of social networking technologies on us and the insights we can gain into our human capacity for morality. There is a reason, of course, that we tend to use existing categories to deal with new phenomena in an evolutionary approach to jurisprudence. Yet, as Easterbrook warned, we should not be drawn into the "law of the horse" approach to answer the sorts of questions the law has already successfully addressed in other subject matter. From this perspective, the metaphor of the "law of the horse" is meant to illustrate that although horses are a unique object in the law, they do not require a distinct set of legal categories. Easterbrook writes:

Lots of cases deal with sales of horses; others deal with people kicked by horses; still more deal with the licensing and racing of horses, or with the care 
veterinarians give to horses, or with prizes at horse shows. Any effort to collect these strands into a course on the Law of the Horse is doomed to be shallow and to miss unifying principles (Easterbrook, 1996, p. 207).

As Easterbrook argues, regulation should not struggle to "match an imperfect legal system to an evolving world that we understand poorly."

This warning should not be taken as a call to set aside a long history of First Amendment or privacy jurisprudence; but it is to advocate instead for thinking critically about the categories we use. While we should not rush to make up a "law of the horse" for social networking technologies, neither should we apply existing categories of First Amendment and privacy doctrine crudely without considering the differences relevant because we may be damaging the very freedoms we hope to protect.

Regulation that pits our privacy interests and our First Amendment interests against the mitigation of the bad behavior that occurs when we are using social networking technologies without considering the phenomenological effects on us clouds our consideration of alternative approaches and ignores the insights we might gain into our way of thinking about morality. The ironic outcome of only vesting social networking technologies with the politically significant values of freedom and liberty does not account for the importance of first considering whether they possess moral significance in changing the very ways we think about freedom and responsibility.

In the end, we must be critical (and honest) about the current state of morality that is on display in our social media interactions and consider what it reveals about how we conceive of our relationship with technology but also the origins of our moral judgments. The central question is whether the mediating influences of social networking technologies call for a departure from traditional assumptions about moral responsibility that draws upon the theories based in utilitarianism or Kantian ethics. There have been several approaches taken to try to shift the focus. One such approach is disclosive ethics, which tries to analyze the morality embedded in technologies that shape ethical practice in the tradition of Latour. Others have advocated a pluralistic ethics on a global scale with an emphasis on virtue ethics (Vallor, 20I2) or feminist ethics (Hamington, 2004). And because social networking technologies allow us to transcend geographical constraints, there is the inevitable problem of national and cultural boundaries that challenge the creation of an applied ethics and contest the idea of a universal moral agent. These insights have caused some to suggest we should consider the effects of virtualization 
on communication and consider how relations of power are represented in online interactions (Turkle, I997). There have also been those who have attached moral agency to artificial agents. Floridi and Sanders, for example, propose to extend the definition of moral agents to include artificial agents as a way of disconnecting moral agency and moral accountability from the idea of moral responsibility so that artificial agents can be held accountable but not responsible (Floridi and Sanders, 2004). Others have emphasized the moral consequences of the development and deployment of technologies as a means of attributing moral responsibility to the intentionality of developers and designers (Nissenbaum, 20I0). Johnson, for instance, argues computer technologies are reflective of the intentionality of their creators and users and leaves no room for the attribution of moral responsibility for what she calls computational artifacts (Johnson, 2006).

The perspective taken here does not accept the premise that the only moral agent is human but neither does it adopt a deterministic or monolithic viewpoint of technology as a driver of social, political, or cultural change (Borgmann, I995. Instead, if the moral subject is coconstituted by the process of technological mediation, then there is not only a consequence for how we conceive of the moral significance of social networking technologies, but how we think about the moral subject and the reasons we give ourselves for our morality.

Traditionally, from a Kantian point of view the condition of moral responsibility depends upon the ability to act and to intend. The Kantian connection between intention and moral responsibility runs deep in our philosophical tradition and is also reflected in the Christian ethos that underpins our legal system and institutional and societal organizations. It is tempting and usual to ground moral responsibility in individual intention, but if technology has the effect of mediating and even changing our perceptions, intentions, and experience, then one has to consider the various ways in which technological artifacts take on moral significance and how our moral reasons for deciding and acting are affected. Johnson and Powers have suggested, for instance, that it is not enough to just look at intentions: "Ascribing more responsibility to persons who act with technology requires coming to grips with the behavior of the technology" (Johnson and Power, 2005, p. I07).

The lack of "ideal liability" in our online lives should not, in other words, translate to a lack of moral responsibility. As more bad behavior occurs online, there may be a need to set aside the distinctly Kantian assumptions that underpin our ideas of moral responsibility to consider 
alternative approaches (Smiley, 20I0). Collective action in our online lives adds another layer of complexity. The intentions and consequences of collective action are even more difficult to know online and blameworthiness difficult to assign when harm has occurred. It might be possible to simply adopt a consequentialist approach that hinges upon the moral assessment of the consequences rather than the intentions, and from this point of view, a different set of considerations is possible, including whether the consequences are productive of a good or contribute to harm. Here the primacy of intention and causation is not the driver of moral responsibility; instead, the harmful consequences figure more centrally and, importantly, engender different solutions. All of this speaks to the possibilities portended by a postphenomenological approach that also opens up the possibility of questioning the modern subject. But there is an irony here too that our relationship with social media reveals about us. We must also be aware that the ways we attempt to escape the confines of the moral subject with a postmodern critique might not always be true to its philosophical origins. The deconstruction of postmodernism allowed us to contest our modernist assumptions about the transcendental subject. Yet, the current trend of politicizing perspectivialism into unassailable moral truths leads us to a new found isolationism because of the normative reasons it presents for who we are and our reasons for doing and action. A postphenomenological approach goes hand in hand with a postmodern approach, and it is with the latter that we have lost our direction. Here social media and the insights it provides for our current ontological state of being can provide a different set of normative questions to ask that refocus our morality on "what I am" in relation to others. The phenomenological influences on our understanding of causation, intention, time consciousness, and personal identity not only speak to ways in which technological development and deployment might be altered and adjusted, but also show us the error of our ways in our current approach to morality. Yet, in order to develop these insights, there first needs to be redirection of the research to better capture and define the phenomenological effects of technology on our consciousness and the consequences it can have on us. These phenomenological effects on us, however, also introduce new questions about the source of our morality. While our modernist approach had us focused on the ethics and morality of our machines, the postphenomenological and postmodern approach should have us focus on finding a new basis for our morality, and this is the intended purpose of this work. So far, there are some troubling aspects to the assumptions we make about global connectivity and morality, for 
instance. While social networking technologies are often heralded as liberating us from our physical limits and enabling connectivity on a global scale, the end result hoped for by some is the development of a sense of multicultural citizenship that transcends the contingencies of geographical place. Missing in this assertion of a newfound sense of global community and a multicultural citizenship is the moral question of what binds us together and guides our human behavior. If we are lifted from physical constraints when we are online, is there a moral consequence for the "contingent connections without which we would not be coming together to construct communities in the first place" (Yack, 20I 2, p. 27). Although protecting the global reach of the Internet is lauded as essential to the moral imperative of freedom and expressive of a universal human right, it might also be accused of ignoring "the role of contingency in our political and moral life for which we are responsible (Yack, 20I 2, p. 24). A recent report issued by the United Nations' Special Rapporteur, for example, advocates a continuing expansion of our online communications and defends anonymous communications and an unregulated Internet as fundamental to the protection of human rights globally. But the universal theory of morality upon which this human rights rhetoric is based and the cyberactivism organized around it disregards a fundamental question about the theory of morality we are promoting with the use of social networking technologies and ignores the fact that assertions of universal freedoms and liberties made under the aegis of a universal concept of morality can also ironically be a tool of oppression and dismissive of localized social and political practices by those who have the power of the technology behind them. The same is true with regard to the distorted postmodernism we assert in our own claims to moral righteousness. As will be addressed, postmodernism and its methodology of deconstruction were not intended to give rise to unassailable truth based on our own moral perspective.

We need to rethink, in other words, the assumptions we make about morality - its substance as well as its origin - in light of social networking technologies. Not only do we need to question whether social networking technologies are inherently moral or immoral because of the political significance we attach to them, but we also need to reconsider how we understand and define our own moral sensibilities. Work is being done to flesh out the moral approach we take when it comes to technology more generally. Verbeek, for example, uses Foucault to formulate an ethical approach that moves beyond the moral subject. Foucault is not generally considered a philosopher of technology, but it is his recognition 
that the structures of power are at work in "concrete practices, objects, and ideas" that Verbeek takes to be important in rethinking morality and the nature of human subjectivity. Verbeek uses Foucault's insight about disciplinary power and the role that it plays in regulating behavior to consider how technology influences the constitution of human subjectivity. In this way, Verbeek suggests that "ethics should not position itself in opposition to power but incorporate power into its approach to morality and moral agency" (Verbeek, 2006, p. 73). This approach inspired by Foucault introduces an aesthetic dimension into the realm of ethics and does not style morality in terms of moral obligations but frames it as "self practices" reflective of the Greek conception of good and the beautiful. Here Verbeek believes technologies need not be destructive of humanity but should be explicitly fashioned to help shape the morality of subjects. There remains the thornier question of exactly what this morality might look like. If we take postphenomenology seriously, then the development and deployment of technology are not our only concerns in shaping the moral subject. We must also consider whether we need a theory of morality to guide us generally and, if so, its normative substance and origin, and right now we are impeding this process by a politicized version of postmodernism that eschews its postmodern promise. Social media can help reveal the mistakes of our current understanding of postmodernism and the morality (or immorality) to which it gives rise. This approach to social media is informed by Heidegger, who speaks about the "saving power" within the danger of technology. Heidegger uses Friedrich Hölderlin's poem "In lieblicher Blaue," or "In Lovely Blue," to explain that Enframing is the danger of technology because it can tempt us not to look further for primal truth. The danger, however, is also the saving power if we are willing to keep searching beyond what we initially are able to know through our praxis with technology. Heidegger explains:

Let us think carefully about these words of Hölderlin. What does it mean to "save"? Usually we think that it means only to seize hold of a thing threatened by ruin, in order to secure it in its former continuance. But the verb "to save" says more. "To save" is to fetch something home into its essence, or order to bring the essence for the first time into its genuine appearing. If the essence of technology, Enframing, is the extreme danger, and if there is truth in Holderlin's words then the rule of Enframing cannot exhaust itself solely with blocking all lighting-up of every revealing all appearing truth. Rather, precisely the essence of technology must harbor in itself the growth of saving power (Heidegger, I993, p. 297).

Hölderlin writes, "where danger is, grows the saving power also." The dangers of our use of social media are obvious. Whether it is cyber 
bullying, revenge porn, or harassment, many have pointed to the danger of who we have become online. It is not, in other words, only about designing technology to shape our moral choices. We may also have to consider what technology has revealed about us to find the saving power in the rethinking of our own morality, and this is the directive of the work that follows. 